\title{
Gender differentials in the social and family life of leprosy patients
}

\author{
SANJAY P. ZODPEY*, RAJNARAYAN R. TIWARI** \& \\ ATUL D. SALODKAR $†$ \\ *Clinical Epidemiology Unit, and Dept. of Preventive and Social \\ Medicine, Govt. Medical College, Nagpur, MS, India \\ **Department of Preventive and Social Medicine, Indira Gandhi \\ Medical College, Nagpur, MS, India \\ $\dagger$ Department of Skin and Leprosy Control Unit, Government Medical \\ College, Nagpur, MS, India
}

\begin{abstract}
Summary A study was carried out at the Leprosy Control Unit, Government Medical College, Nagpur, India, to investigate gender differentials in the social and family life of leprosy patients. The study included 486 (268 males and 218 females) leprosy patients, who were diagnosed and registered at least 1 year prior to the data collection. It was observed that leprosy patients were isolated and refrained from various activities in the family. However, the effect of disease on this isolation was significantly greater in females as compared to males. Similarly, although, men and women were both affected in terms of their social life, women suffered more isolation and rejection from the society. The current study describes the gender differentials in the social and family life of leprosy patients in Central India.
\end{abstract}

\section{Introduction}

Even today, leprosy remains a public health problem in many countries of the world. The South-East Asia region accounts for $90 \%$ of the global leprosy burden and India alone accounts for 55\%. With the introduction of multi-drug therapy (MDT) in 1982, the leprosy situation in the world changed dramatically. In 1997, for the first time, the number of registered cases reported globally was less than 1 million $(0.8$ million $) .{ }^{1}$ With the introduction of MDT, India too has had a significant reduction in the prevalence rates in many states, where MDT is in operation. ${ }^{2}$ However, reduction in registered prevalence alone is not sufficient as the social consequences of the disease on the life of the patient are often severe and persist even after its cure.

Leprosy holds a unique position among communicable diseases because of the frequency of deformity, physical handicap and ostracism due to social stigma. ${ }^{3}$ This disease is a highly

*Correspondence to: S.P. Zodpey, 305 Hanuman Nagar, Nagpur 440 009, MS, India 
stigmatized one and may lead to premature social death among patients. ${ }^{4}$ Once a person is correctly diagnosed as a leprosy patient, his/her roles in the family and society are restricted and constrained. ${ }^{4}$

Women are considered a socially vulnerable group, ${ }^{5}$ and marriage is difficult and acceptance is not total. ${ }^{6}$ The social impact of the disease affliction has been described by earlier researchers, ${ }^{3-5,7-10}$ but few have investigated gender differentials in the social impact of leprosy. ${ }^{5,11-13}$ The issue is of considerable significance for women, who are accorded a low social status in many communities in India and receive differential treatment from the members in the family and the wider society. Thus the understanding of the gender differentials in the social and family life of leprosy patients is important. We have performed a study to investigate the gender differentials in the social and family impact of leprosy in Central India.

\section{Materials and methods}

The present study was carried out at the Government Medical College Hospital, Nagpur, India. The study centre is a tertiary care hospital with a separate Leprosy Control Unit. A total of 486 patients attending this hospital and who were diagnosed and registered as leprosy patients at least 1 year prior to the data collection for this study, were recruited. Data were collected from this group using a structured interview schedule which included questions seeking information on demographic characteristics (age, sex, socio-economic status, areas of residence and marital status), impact of disease on daily life and attitude of family members, the impact of disease on social life and experiences of interviewees regarding the effects of disease on their lives. The structural interview was designed by framing appropriate questions to obtain required information and were pilot tested before its final use. The socioeconomic status was recorded by using the Modified Kuppuswamy's scale of socio-economic status (SES) classification, using occupation, education and per capita income as parameters. This is a 5-point scale, with class I representing the highest socio-economic (Upper) and class $\mathrm{V}$ representing the lowest (Lower) status. Classes II, III and IV are represented by Upper middle, Lower middle and Upper lower SES, respectively. ${ }^{14}$ Statistical analysis was based on the use of the $\chi^{2}$ test.

\section{Results}

Table 1 describes the subjects by the demographic characteristics. The study included 268 $(55.1 \%)$ males and 218 (44.9\%) females. $39.7 \%$ subjects were in the age group 20-40 years followed by $35 \%$ in under 20 years. The majority of the patients belonged to upper lower and lower middle socio-economic status and $63.9 \%$ patients were from urban areas. A total of 264 $(54.3 \%)$ subjects were married.

Impact of disease on daily life of leprosy patients and attitude of their family members is described in Table 2. The table presents evidence that the study subjects were isolated or refrained from various activities in the family. However, the effect of disease on this isolation was greater in females as compared to males for all the parameters. Impact of disease on 
Table 1. Distribution of subjects by demographic characteristics

\begin{tabular}{lccc}
\hline & Males $(n=268)$ & $\begin{array}{l}\text { Females }(n=218) \\
n(\%)\end{array}$ & $\begin{array}{l}\text { Total }(n=486) \\
n(\%)\end{array}$ \\
Characteristics & $n(\%)$ & & \\
\hline Age (years) & & $72(33.0)$ & $170(35.0)$ \\
$<20$ & $98(36.6)$ & $91(41.7)$ & $193(39.7)$ \\
$20-40$ & $102(38.1)$ & $55(25.3)$ & $123(25.3)$ \\
$40+$ & $68(25.3)$ & $19(8.7)$ & $41(8.4)$ \\
Socio-economic status & $22(8.2)$ & $88(40.4)$ & $196(40.3)$ \\
Lower (class V) & $108(40.3)$ & $66(30.3)$ & $146(30.1)$ \\
Upper lower (class IV) & $80(29.9)$ & $37(16.9)$ & $19(3.9)$ \\
Lower middle (class III) & $47(17.5)$ & $8(3.7)$ & $311(63.9)$ \\
Upper middle (class II) & $11(4.1)$ & $124(56.9)$ & $175(36.1)$ \\
Upper (class I) & & $94(43.1)$ & $264(54.3)$ \\
Area of residence & $187(69.8)$ & $130(59.6)$ & $190(39.1)$ \\
Urban & $81(30.2)$ & $69(31.7)$ & $32(6.6)$ \\
Rural & $134(50.0)$ & $19(8.7)$ & \\
Marital status & $121(45.1)$ & & \\
Married & $13(4.9)$ & & \\
Unmarried & & & \\
Others & & & \\
\hline
\end{tabular}

social life of leprosy patients is depicted in Table 3. Although men and women were both affected in terms of their social life, women suffered more isolation and rejection from family and society. The differences in impact of the disease on their social life between males and females were statistically significant. Table 4 shows personal experiences of the study subjects regarding effects of disease on their lives. Although the lives of both men and women were affected by the disease, females showed a significantly greater effect of disease on their lives as compared to males.

Table 2. Impact of disease on day to day life and attitude of family members

\begin{tabular}{lllc}
\hline Factors & $\begin{array}{l}\text { Males }(n=268) \\
n(\%)\end{array}$ & $\begin{array}{l}\text { Females }(n=218) \\
n(\%)\end{array}$ & $P$ value $\left(\chi^{2}\right.$ test $)$ \\
\hline $\begin{array}{l}\text { Isolated/refrained from } \\
\text { Cooking }^{\text {a }}\end{array}$ & - & $79(36.2)$ & - \\
Touching others & $38(14.2)$ & $67(30.7)$ & $<0.0001$ \\
Eating together & $19(7.1)$ & $50(22.9)$ & $<0.0001$ \\
Sleeping together & $54(20.1)$ & $59(27.1)$ & 0.073 \\
Sex & $33(24.6)$ & $43(33.1)$ & 0.130 \\
Using common articles of daily use & $43(16.0)$ & $65(29.8)$ & $<0.001$ \\
Mixing with other family members & $40(14.9)$ & $59(27.1)$ & 0.001 \\
Decision making in family matters & $27(10.1)$ & $23(10.6)$ & - \\
Breastfeeding the child & - & $25(49.0)$ & 0.864 \\
& & & \\
\hline
\end{tabular}

\footnotetext{
${ }^{\text {a }}$ Four male subjects were involved in cooking, who were staying alone.

${ }^{\mathrm{b}}$ Information related to sexual relationship was obtained from only married study subjects.

${ }^{\mathrm{c}}$ Information related to breastfeeding was obtained from female subjects $(n=51)$ who were breast feeding their child at the time of diagnosis.
} 
Table 3. Impact of disease on social life

\begin{tabular}{lllc} 
Factors & Males $(n=268)$ & Females $(n=218)$ & $P$ value $\left(\chi^{2}\right.$ test $)$ \\
\hline Refrained from & & & \\
Going out & $29(10.8)$ & $83(38.1)$ & $<0.0001$ \\
Travelling & $32(11.9)$ & $76(34.9)$ & $<0.0001$ \\
Attending festivals & $28(10.4)$ & $89(40.8)$ & $<0.00001$ \\
Going to the worship $^{\text {a }}$ places & $03(4.3)$ & $08(10.8)$ & 0.141 \\
Attending marriages & $36(13.4)$ & $79(36.2)$ & $<0.0001$ \\
Attending family functions & $32(11.9)$ & $77(35.3)$ & $<0.0001$
\end{tabular}

\footnotetext{
${ }^{a}$ Information was obtained from subjects who used to attend worship places before the diagnosis $(\mathrm{males}=70$, females $=74$ ).
}

\section{Discussion}

Gender inequalities in health have a significant effect on women's health. ${ }^{11}$ There are, however, many gender inequalities related to health and disease. The recently published review highlighted that there are many gender differences, biological as well as sociocultural, which are related to leprosy. ${ }^{11}$ In leprosy gender inequalities could be more serious, as it is highly stigmatized disease. ${ }^{11,}{ }^{12}$ Although both men and women are negatively affected in most situations, the extent of the impact is more in women than men. ${ }^{12}$ In India ${ }^{8}$ women could not work as efficiently as other female members of the family due to affliction by leprosy.

Considering socio-cultural outcome of disease, several studies indicated that the women were more affected by leprosy, ${ }^{11}$ they suffered more isolation, rejection from spouses, children and relative, loss of freedom to touch and have more restrictions than men in India. ${ }^{12}$ Women with leprosy are less likely to have the opportunity. ${ }^{14}$ The empirical evidence presented in the previous studies demonstrated the importance of analysing the situation of leprosy patients from the gender perspective as it has significant implications for disease control.

The degree to which men and women leprosy patients were isolated from their family activities and events is evident from Table 2. It was observed that by and large women were more isolated from all activities than men. Seventy-nine $(36.2 \%)$ females refrained from cooking activity while $22.9 \%$ refrained from eating together. Isolation from touching others was again a strong reaction that many women $(30.7 \%)$ faced, unlike men $(14.2 \%)$. It was also

Table 4. Experiences of study subjects about effects of disease on their lives

\begin{tabular}{lccc}
\hline Personal experiences & Males $(n=268)$ & Females $(n=218)$ & $P$ value $\left(\chi^{2}\right.$ test $)$ \\
\hline Support of spouse $^{\mathrm{a}}$ & $69(51.5)$ & $39(30.0)$ & $<0.0001$ \\
Support of other family members & $113(42.2)$ & $55(25.2)$ & $<0.0001$ \\
Impact on day to day life & $39(14.6)$ & $75(34.3)$ & $<0.0001$ \\
Impact on social life & $34(12.7)$ & $84(38.5)$ & $<0.0001$ \\
Marriage prospects & $7(2.6)$ & $18(8.3)$ & $<0.005$ \\
Insulting treatment by family members & $17(6.3)$ & $56(25.7)$ & $<0.0001$ \\
\hline
\end{tabular}

\footnotetext{
${ }^{\text {a }}$ Information was obtained only from married study subjects.
} 
observed that $49 \%$ of the breastfeeding mothers did not breastfeed their children. Loss of freedom to touch and to be touched, especially with their children, symbolized rejection. Similarly, they were isolated from sleeping in the same room along with the other family members and mixing with them. More women suffered from isolation from having sex with their spouses, using common articles of daily use and were not involved in decision making in the family matters.

Such isolation from domestic roles develops among women a self-image of being a less valued member of the family. ${ }^{16}$ Earlier studies ${ }^{4,17}$ also demonstrated isolation of leprosy patients in their own family from daily activities and attitudes of rejection from their own family members. These issues have not been extensively studied previously in relation to gender in Central India population.

The disease not only affects daily functioning in the family, but also considerable restrictions are enforced on patients due to the fear of social stigma. The impact of disease on the social life of leprosy patients is evident from Table 3. It is observed that more women seem to have these restrictions than men. The proportion of women who refrained from going out, travelling, attending festivals, going to the worship places, attending marriages and even attending family functions was significantly greater than men. Important gender differences were apparent on the social impact of the disease. While both men and women were negatively affected in most situations, the extent of the impact was more in women than men. Such restrictions clearly increase morbidity in women patients, and affect their treatment. ${ }^{12}$

These findings are further endorsed by the experiences reported by the subjects of the effect of disease on their lives (Table 4). A total of 18 (8.3\%) of women admitted that the disease affliction affected their marriage prospects compared to $2.6 \%$ of men. Women might delay seeking medical care when they suspect having leprosy, since being diagnosed with leprosy might severely reduce their chances of marriage or may affect their position and role in the household when married.

The source of patients recruited for this study needs to be borne in mind when interpreting the findings. The study population is of those attending a tertiary health care facility and they may not be representative of all patients. There is no control group to demonstrate what gender differentials exist in Central India in people without leprosy.

In conclusion, important gender differences have been demonstrated in the family and social impact of leprosy. Although men and women were both affected in terms of their family and social life, women suffered more isolation and rejection from family and society. It can be seen from the current study that the family and social problems faced by women suffering from leprosy were mainly due to the associated social stigma. The need to reduce social stigma is therefore emphasized. To overcome this problem, the community educational component of leprosy control programmes needs to be strengthened. Perhaps groups such as Women's Clubs (which exist in many villages), women school teachers or women members of Panchayat (local village government) can be involved in educating women as well as community. ${ }^{12}$ However, it is the attitudes of the community and the family that need to change, rather than the women themselves.

\section{References}

1 WHO. Health Situation in the South-East Asia region, 1994-1997. WHO, Geneva , pp 11, 100-101.

2 Mittal BN. National strategy for elimination of leprosy in India. Ind. J. Lepr., 1992; 65: 513-520. 
${ }^{3}$ Reddy NBB, Satpathy SK, Krishnan SAR, Srinivasan T. Social aspects of leprosy: a case study in Zaria, Northern Nigeria. Lepr. Rev., 1985; 56: 23-25.

${ }^{4}$ Valencia LB. Social science research on social dimensions of leprosy: where are we going from here? Int. J. Lepr., 1989; 57: 847-863.

5 Kaur H, Ramesh V. Social problems of women leprosy patients - a study conducted at 2 urban leprosy centres in Delhi. Lepr. Rev., 1994; 65: 361-375.

${ }^{6}$ Kumar A, Anbalagan M. Socio-economic experiences of leprosy patients. Lepr. Ind., 1983; 55: 314-321.

${ }^{7}$ Ramu G, Dwiwedi MP, Iyer CGS. Social reaction to leprosy in a rural population in Chingleput District (Tamilnadu). Lepr. Ind., 1975; 43: 156-169.

8 Kant VP. Socio-economic problems of leprosy patients: and their relatives in Gujarat state. Ind. J. Lepr., 1984; 56: 889-899.

9 Chakravartti MR. Social dimension of leprosy: a plea to solve social problems. Ind. J. Lepr., 1986; 58: 609-614.

${ }^{10}$ Kant VP. Solutions of some of the social problems of leprosy patients. Ind. J. Lepr., 1988; 60: 427-429.

11 Grand AL. Women and leprosy: a review. Lepr. Rev., 1997; 68: 203-211.

12 Rao S, Garole V, Walawalkar S et al. Gender differentials in the social impact of leprosy. Lepr. Rev., 1996; 67: 190-199.

13 Rathgeber E, Vlassoff C. Gender and tropical diseases: a new research focus. Soc. Sci. Med., 1993; 37: 513-520.

14 Mahajan BK, Gupta MC. Social environment. In: Textbook of preventive and social medicine. Jaypee Bros, New Delhi, pp 82-86, 1991.

15 Valencia LB. Socio-economic research in the Philippines with special references to leprosy. SE Asian Trop. Med. Pub. Hlth, 1983; 14: 29.

16 Vlassoff C, Bonilla E. Gender differences in the determinants and consequences of tropical diseases: what do we know? J. Bio. Sci., 1994; 26: 37-53.

17 Kushawas SS, Govila AK, Upadhyay S, Kushawas J. A study of social stigma among leprosy patients attending a leprosy clinic in Gwalior. Lepr. Ind., 1981; 53: 221-225. 